\title{
Study on the Teaching Mode of BIM in Chinese Colleges
}

\section{Hui Chen}

Yunnan Technology and Business University, Kunming, Yunnan, 651701

Keywords: BIM; Chinese colleges; teaching mode

\begin{abstract}
The application of BIM technology in the teaching of colleges and universities can abstract theoretical knowledge, promote the improvement of teaching quality, and effectively improve teaching efficiency. Therefore, this article researches the application of BIM technology in college teaching. Through the analysis of the status quo, problems can be found out and countermeasures can be studied to finally improve the teaching quality.
\end{abstract}

\section{Introduction}

In recent years, practical education in colleges and universities has become more and more important to people. In 2012, seven departments including the Ministry of Education, the Central Propaganda Department, and the Ministry of Finance mentioned "Important Understanding of the Importance of Educating People in Colleges and Universities" in the "Opinions of the Ministry of Education and Other Departments on Further Strengthening the Practice of Educating People in Colleges and Universities". It is pointed out that "the reform of practical teaching methods is the key to promoting the reform of practical teaching and the reform of personnel training models." "Building Information Modeling" (hereinafter referred to as BIM) is a data technology tool for engineering technology and management. It has a transformative impact on the construction of practical teaching systems in colleges and universities. It is one of the important means for people's reform of the teaching curriculum system recently. By integrating BIM into the education of students, their understanding of architecture, design and related factors can be changed, and the level of practical teaching and teaching effectiveness can be improved. It can be said that the application and promotion of BIM technology in the engineering field has created a brand-new platform for the application of information technology in colleges and universities.

\section{Status of BIM Technology Application at Home and Abroad}

BIM technology first appeared in the architectural field and developed in the western developed countries. It gradually matured at the beginning of this century. While being accepted by the market and society, foreign universities have also increased the application of BIM in scientific research and teaching work in universities. The application rate of BIM in the US construction industry also increased from 28\% in 2007 to $71 \%$ in 2012 [1]. The solution to the lack of BIM talents lies in the BIM teaching reform in universities. For example: In the Department of Construction Management of the University of Colorado in the United States, BIM modeling teaching is used instead of CAD teaching in the first grade to cultivate students' modeling capabilities, and to create a basic platform for BIM teaching and application of courses such as late structure and cost. However, the research of Becerik-Gerber et al. indicated that even in the United States, 36\% of the BIM undergraduate teaching programs do not include the BIM curriculum, and one fifth of the departments did not conduct the BIM teaching reform program [2]. In China, in 2005, the Architectural Institute of South China University of Technology and Eurotech Co., Ltd. jointly established the BLM-BIM Laboratory for Architectural Life Cycle Management (BLM). In the year, BIM was taken as the main research direction of the laboratory. Subsequently, South China University of Technology, Tsinghua University, Tongji University and Harbin Institute of Technology co-edited the first Chinese book "BLM Theory and Practice Series" that introduced the building life cycle management and BIM theory and practice. In addition, teachers from South China University of 
Technology also compiled BIM-related teaching materials such as Revit Building Architectural Design Tutorial and Introduction to Digital Architectural Design, and were adopted by many domestic institutions. Based on the development trend of BIM abroad and domestically, it is necessary to carry out the reform of the personnel training methods in order to improve the overall quality of engineering management professionals and enhance the competitiveness of engineering management graduates [3]. In recent years, the informatization software led by the field of cost management has gradually matured, with the development of a series of project cost management software, such as Grundart, Tsinghua Swell, God Machine, Luban, etc., and the maturity of the market. The improvement created a preliminary platform foundation for the establishment of a domestic engineering informatization model. Various domestic software development companies actively cooperated with colleges and universities to establish informationized digital laboratories and further promoted the research and application of BIM software in practical teaching in universities.

\section{The Main Problems in the Application of BIM Technology in College Teaching}

To realize informationization, it is necessary to do a good job of collecting data in a timely manner. The collected data needs to be classified in a timely manner to form a complete information database. The focus of BIM technology is to use a database specifically for storing geometric information, physical information, and topology information, and build a shared platform for project-related parties to manage the project on this platform. Different engineering projects have differences in architectural structures, technologies, methods, and management models. These engineering information also affect the development of BIM technology to some extent. According to the survey, the development of BIM technology in the future requires a more complete database. In the implementation. In recent years, software development companies in many countries have also actively cooperated with universities to develop BIM technology-related software. In the application process of BIM software, there are obstacles in interworking between different softwares. From this we can see that there is still a gap between the domestic technology and the developed countries in the development of BIM software. In addition, in the teaching of universities, although the BIM technology has been promoted, the convergence of different professional courses has also become a problem to be solved in the education link. The problem.

There is a large demand for talents for BIM technology applications, and the training of BIM technicians is also a prerequisite for the training of applied talents. At present, the demand for BIM technical talents in the construction industry is increasing, and colleges and universities are also in urgent need of relevant reforms. Only by ensuring that colleges and universities have strong BIM technical personnel can they effectively infiltrate BIM technology in the teaching process. However, judging from the current development, the teachers of universities and colleges still need to strengthen the professional quality of BIM technology.

The BIM technology in the university curriculum is not well developed. On the one hand, because the management has not paid enough attention to it, more attention is paid to scientific research results and neglects teaching; on the other hand, it is due to insufficient research funding. Limit its advantages and effective play. The uneven funding for research and teaching in different institutions also slows the application of BIM technology in some universities to a certain extent, which makes it difficult to solve the demand problem.

\section{BIM Technology Applied in College Teaching}

In order to effectively apply the BIM technology to the curriculum system of the engineering management major, and to realize the education goal of cultivating information technology talents who understand the technology and understand the management, under the concept of CDIO (Conceive conception, design design, implementation of Implement, Operate operation), Students learn engineering theories, techniques, and experiences in an active, hands-on, and organic way [4]. Using the integrated features of the BIM model information, we have opened up communication 
between courses, between theory and practice, between on-campus teaching and off-campus teaching, relying on BIM technology and network information platform, and constructing theory of organic theory based on practice-led thinking. Curriculum system, highly practical curriculum system, and multi-channel social education system's "ternary education system with characteristics."

To change the teaching philosophy of first theory and then practice, to set up experimental courses prior to theoretical courses, and to realize the dominant idea that theory comes from practice. The "Building Informatization Model" itself covers many courses in the major, but the modeling work of the model itself is relatively simple compared with the future applications. At the same time, the building informatization model has its own five characteristics of visualization, coordination, simulation, optimization, and plotting. It is easy for beginners to understand and understand, and can greatly improve the teaching efficiency and enthusiasm of students. In the past, BIM modeling work was interspersed in various specialized courses. Teachers and students not only experienced many features of a specific project, but also had to familiarize themselves with the process. They may even need to use different software to complete the tedious modeling work and create professional teaching hours. Tension, but also makes possible similar modeling work repeated in different professional courses, a great waste of limited teaching resources. At this stage, although independent BIM pilot courses cannot temporarily completely replace CAD courses (determined by realistic social work), BIM modeling experiment courses should be independently established on the basis of CAD courses in order to serve future professional courses. Learn. The author takes Guanglian civil engineering and installation modeling software as an example. The software can not only quickly create 3D models from three-dimensional design software Revit, ArchiCAD, MegiCAD, Tekla and 2D design software PKPM, Tianzheng, and Haochen software, but also quickly build their own 3D models. The compatibility of software can effectively save the time of modeling, training efficiency, and cost of different courses under different software applications. This should first be based on the independent professional basic BIM curriculum. For example: At the University of Nebraska-Lincoln (Russell et al., 2014), BIM courses are set up in the basic courses of freshmen and sophomores in the course of architectural engineering.

The actual practice of practical teaching is embodied in the practical teaching section. The fundamental purpose of theoretical course study is to solve practical application problems. Through the realization of the "engineering informatization model" established in the experimental course, the "longitudinal" integration of the professional curriculum system is achieved, and many related, similar, and even far-reaching courses are organically linked to reinforce the integrity of the curriculum system in teaching work. Degree of integration and degree of integration. For example: Engineering Graphics, Introduction to Construction Engineering, Architectural Structure, Architectural Mechanics, Engineering Valuation, Project Management, etc. Many courses under the information model of the same engineering project, practice teaching, even advanced mathematics, project management, etc. The basic curriculum can also be applied under this model to achieve the students' applicability to professional courses and even basic courses. The author believes that one of the key issues in the effective use of BIM at this stage is: A unified experimental teaching case that serves different professional courses should be set up, and a building informatization model with common platforms for various professional courses should be established. This will not only save teaching resources but also promote the "organicity" of professional course system construction. In the face of more complicated curriculum systems and technical and management courses with a large span of professional curriculum teaching, it is necessary to achieve a breakthrough in a project (one model): gather procedural information data covering the entire life cycle of the project. In a model, the use of multiple perspectives in different courses will simplify the teaching process, improve the teaching effect, and implement the diversity of teachers' teaching methods. At the same time, it will also be conducive to students' initiative and self-consciousness in learning, which will benefit later student training mechanisms. The establishment. Taking an office building as a case, it runs through all courses, realizes multiple uses of one modeling, and repeatedly strengthens experiment case exercises.

In the traditional university teaching, the basics are all accomplished through textbook 
knowledge and teacher presentations. Because the knowledge content of architectural majors is more complicated, traditional teaching methods make it impossible for students to completely understand the knowledge. Therefore, it is of great significance to strengthen the application of BIM technology in college teaching. It is not only the embodiment of building informatization in teaching, but also the visualization of theoretical knowledge. In college teaching, it is necessary to strengthen the reform of teaching methods, to achieve the flexibility of teaching methods, to maximize the application of BIM technology in the teaching process, and to improve the quality of teaching. In addition to being able to learn related professional theoretical knowledge, students can also expand the use of certain BIM technologies, integrate relevant building information efficiently, and build a complete and visual knowledge system. This plays an important role in promoting the improvement of students' comprehensive ability.

\section{Conclusion}

In the traditional university teaching, the basics are all accomplished through textbook knowledge and teacher presentations. Because the knowledge content of architectural majors is more complicated, traditional teaching methods make it impossible for students to completely understand the knowledge. Therefore, it is of great significance to strengthen the application of BIM technology in college teaching. It is not only the embodiment of building informatization in teaching, but also the visualization of theoretical knowledge. In college teaching, it is necessary to strengthen the reform of teaching methods, to achieve the flexibility of teaching methods, to maximize the application of BIM technology in the teaching process, and to improve the quality of teaching. In addition to being able to learn related professional theoretical knowledge, students can also expand the use of certain BIM technologies, integrate relevant building information efficiently, and build a complete and visual knowledge system. This plays an important role in promoting the improvement of students' comprehensive ability.

\section{References}

[1] Wang Jianchao, Zhang Dingyuan, Zhou Jinghai. Application of BIM Technology in the Teaching of Specialized Courses in Architectural Universities[J]. Advanced Architectural Education, 2017(1):161 164.

[2] Liao Ling, Deng Langni, Liu Xiaofeng, Lu Yunpeng. Research on the Teaching Reform of Civil Engineering Technology Based on BIM Technology[J]. Sichuan Building Materials, 2017(1): 201 202.

[3] Li Juanfang, Shang Shiyu, Zhu Yahong. Application of BIM technology in the teaching of civil engineering in universities [J]. Sichuan Building Materials, 2016(7): 201 202.

[4] Hu Shaolan, Liu Yuejun. Application of BIM technology in undergraduate teaching of architecture [J]. Manager, 2016(11):369. [5] Zeng Wenhai, Fu Weiming. BIM technology in teaching in colleges and universities. Applied Research[J]. Journal of Heilongjiang College of Ecological Engineering, 2014(6): 85 86. 